\title{
Common Bile Duct Obstruction Secondary to a Periampullary Diverticulum
}

\author{
Anastasios J. Karayiannakis ${ }^{a}$ Helen Bolanaki $^{a}$ \\ Nikos Courcoutsakis ${ }^{b}$ Georgios Kouklakis ${ }^{c}$ \\ Erchan Moustafa $^{a}$ Panos Prassopoulos $^{b}$ \\ Constantinos Simopoulos ${ }^{a}$
}

${ }^{a}$ Second Department of Surgery, ${ }^{b}$ Department of Radiology and Medical Imaging and 'Gastrointestinal Endoscopy Unit, Democritus University of Thrace Medical School, Alexandroupolis, Greece

\section{Key Words}

Ampulla of Vater - Diverticulum - Duodenum - Complications · Jaundice · Periampullary

\begin{abstract}
Periampullary duodenal diverticula are not uncommon and are usually asymptomatic although complications may occasionally occur. Here, we report the case of a 72-year-old woman who presented with painless obstructive jaundice. Laboratory tests showed abnormally elevated serum concentrations of total and direct bilirubin, of alkaline phosphatase, of $\gamma$-glutamyl transpeptidase, and of aspartate and alanine aminotransferases. Serum concentrations of the tumor markers carbohydrate antigen 19-9 and carcinoembryonic antigen were normal. Abdominal ultrasonography showed dilatation of the common bile duct (CBD), but no gallstones were found either in the gallbladder or in the CBD. The gallbladder wall was normal. Computed tomography failed to detect the cause of CBD obstruction. Magnetic resonance imaging and magnetic resonance cholangiopancreatography revealed a periampullary diverticulum measuring $2 \mathrm{~cm}$ in diameter and compressing the CBD. The pancreatic duct was normal. Hypotonic duodenography demonstrated a periampullary diverticulum with a filling defect corresponding to the papilla. CBD compression by the diverticulum was considered as the cause of jaundice. The patient was successfully treated by surgical excision of the diverticulum. In conclusion, the presence of a periampullary diverticulum should be considered in elderly patients presenting with obstructive jaundice in the absence of CBD gallstones or of a tumor mass. Non-interventional imaging studies should be preferred for diagnosis of this condition, and surgical or endoscopic interventions should be used judiciously for the effective and safe treatment of these patients.
\end{abstract}

Anastasios J. Karayiannakis, MD, MSc, PhD
Second Department of Surgery, Democritus University of Thrace Medical School GR-68100 Alexandroupolis (Greece)

Tel. +30 255107 4006, E-Mail akarayan@usa.net 


\section{Introduction}

Duodenal diverticula are mostly true or primary diverticula representing extraluminal mucosal outpouchings devoid of muscle layer. In $90 \%$ of cases they are solitary and approximately $75 \%$ of them are located in the second part of the duodenum, mostly in its concave medial aspect adjacent to the ampulla of Vater. When they arise within 2-3 cm from the ampulla of Vater they are named periampullary, peripapillary or paravaterian diverticula. Diverticula containing the papilla (intradiverticular papilla) are also known as ampullary diverticula. Diverticula arising in a range of 2-3 cm from the ampulla of Vater but not containing the papilla are also referred to by some authors as juxtapapillary or juxta-ampullary duodenal diverticula [1-3].

Periampullary diverticula are not rare. Their prevalence varies from 0.16 to $22 \%$ depending on the diagnostic method used (barium meal, endoscopic retrograde cholangiopancreatography or autopsy) and increases with age [2,3]. The majority of periampullary diverticula are asymptomatic and are found incidentally during endoscopic or imaging procedures, but occasionally non-pancreaticobiliary or pancreaticobiliary complications may occur [1-5]. Non-pancreaticobiliary complications include hemorrhage, perforation or fistula formation and enterolith formation and are mostly related to inflammation of the diverticulum. Pancreaticobiliary complications such as recurrent gallbladder or bile duct stones, obstructive jaundice, cholangitis, acute or chronic pancreatitis can result from compression by a large diverticulum, due to motility dysfunction of the sphincter of Oddi or because of reflux of intestinal content into the bile ducts and bacterial overgrowth [6-9]. Obstructive jaundice in the absence of gallstones due to a periampullary duodenal diverticulum is also known as Lemmel's syndrome and may be recurrent or complicated by cholangitis and is attributed to mechanical external compression of the terminal bile duct by the diverticulum [10]. Herein we report a patient presenting with obstructive jaundice caused by a periampullary duodenal diverticulum who was successfully treated by surgical excision of the diverticulum.

\section{Case Report}

A 72-year-old woman presented with painless obstructive jaundice of 5 days duration when she noticed yellow-colored scleras and brown discoloration of urine. On physical examination, she was icteric with mild tenderness in the right upper abdominal quadrant. Laboratory tests showed elevated liver function tests with total bilirubin of $7.8 \mathrm{mg} / \mathrm{dl}$, direct bilirubin of $6.2 \mathrm{mg} / \mathrm{dl}$, alkaline phosphatase of $231 \mathrm{U} / \mathrm{l}, \gamma$-glutamyl transpeptidase of $307 \mathrm{U} / \mathrm{l}$, aspartate aminotransferase of $68 \mathrm{U} / \mathrm{l}$ and alanine aminotransferase of $96 \mathrm{U} / \mathrm{l}$. Serum concentrations of the tumor markers carbohydrate antigen 19-9 and carcinoembryonic antigen were normal.

Abdominal ultrasonography showed dilatation $(18 \mathrm{~mm}$ ) of the common bile duct (CBD) but no stones. The gallbladder was normal. Computed tomography failed to detect the cause of obstruction. Magnetic resonance imaging and magnetic resonance cholangiopancreatography (MRCP) revealed a periampullary diverticulum measuring $2 \mathrm{~cm}$ in diameter and compressing the CBD (fig. 1). The pancreatic duct was normal. These findings were confirmed by hypotonic duodenography (ig. 2).

At operation, the duodenum and the posterior aspect of the pancreatic head were completely mobilized, and the distal part of the CBD was dissected. The diverticulum was found deforming and compressing the CBD with its neck protruding between common bile and pancreatic ducts (fig. 3 ). After opening the sac of the diverticulum the papilla was found located inside the diverticulum 
(fig, 4). The sac of the diverticulum was excised and closed with fine absorbable sutures. The duodenal wall over the diverticulum was oversewn. Cholecystectomy was also performed. Postoperatively, abnormal liver function tests returned to normal within one week.

\section{Discussion}

Primary or true duodenal diverticula represent mucosal outpouchings devoid of muscle layer. Their incidence varies from 0.16 to $22 \%$ depending on the diagnostic method used (barium meal, endoscopic retrograde cholangiopancreatography or autopsy) and increases with age [2,3]. They are usually solitary and occur mostly in the concave medial aspect of the second part of the duodenum adjacent to the ampulla of Vater also named juxtapapillary duodenal diverticula, periampullary or paravaterian diverticula. They are classified into three types depending on the position of the papilla in relation to the diverticulum. In type I, which is the most common, the major papilla is located within the diverticulum, in type II the papilla is located in the margin of the diverticulum, while in type III it is located near the diverticulum.

On barium studies, periampullary diverticula are typically demonstrated as contrast-filled outpouchings arising from the medial side of the descending duodenum. Filling defects, if present, commonly represent food fragments, retained air or the protruding into the diverticulum ampulla, as in this case. On computed tomography scans periampullary diverticula are characterized by the presence of air-contrast level within a juxtaduodenal outpouching. On magnetic resonance imaging, the T2-weighted images show a hyperintense fluid level with signal void above it due to the presence of air. Half-Fourier Acquisition Single-Shot Turbo Spin-Echo (HASTE) images and true Fast Imaging with Steady Precession (FISP) images demonstrate the diverticular wall as well as its relation to the papilla [11]. MRCP is the method of choice when assessing the consequences of a diagnosed diverticulum on the CBD and to differentiate the diverticulum from pseudocysts or cystic tumors of the pancreatic head.

The majority of periampullary diverticula are asymptomatic; however, biliopancreatic complications such as recurrent biliary calculi, obstructive jaundice (Lemmel's syndrome), cholangitis, acute or chronic pancreatitis can result from mechanical compression by a large, distended due to poorly emptying diverticulum or due to motility dysfunction of the sphincter of Oddi, reflux of intestinal content into the ducts and bacterial overgrowth [6-9]. Complications related to inflammation such as diverticulitis, hemorrhage, perforation or fistula formation may also occur [1-5].

In cases of biliary obstruction, excision of the diverticulum (diverticulectomy) is an appropriate procedure, but it can be difficult and is associated with a significant mortality and morbidity [10]. Bypass procedures such as choledochoduodenostomy, Roux-en-Y choledochojejunostomy and procedures such as duodenal diverticulization and duodenojejunostomy aiming at duodenal decompression and inversion or reconstruction of the diverticular sac through a duodenotomy may also be useful [12]. Endoscopic sphincterotomy or stenting are reasonable alternatives in high-risk patients [13-15] although failure and complication rates are considerable as the papilla is most often located in or adjacent to the diverticulum [16].

In summary, periampullary diverticula are found mostly in elderly patients and may cause non-pancreaticobiliary or pancreaticobiliary complications. We present a patient 
with obstructive jaundice caused by a periampullary duodenal diverticulum (Lemmel's syndrome) who was successfully treated by surgical excision of the diverticulum. The presence of a periampullary diverticulum should be considered in elderly patients presenting with obstructive jaundice complicated or not by cholangitis in the absence of CBD gallstones or of a tumor mass. Non-interventional imaging studies should be preferred for the diagnosis of a periampullary diverticulum causing obstructive jaundice, and technically demanding surgical or endoscopic interventions should be used judiciously for the effective and safe treatment of these patients.

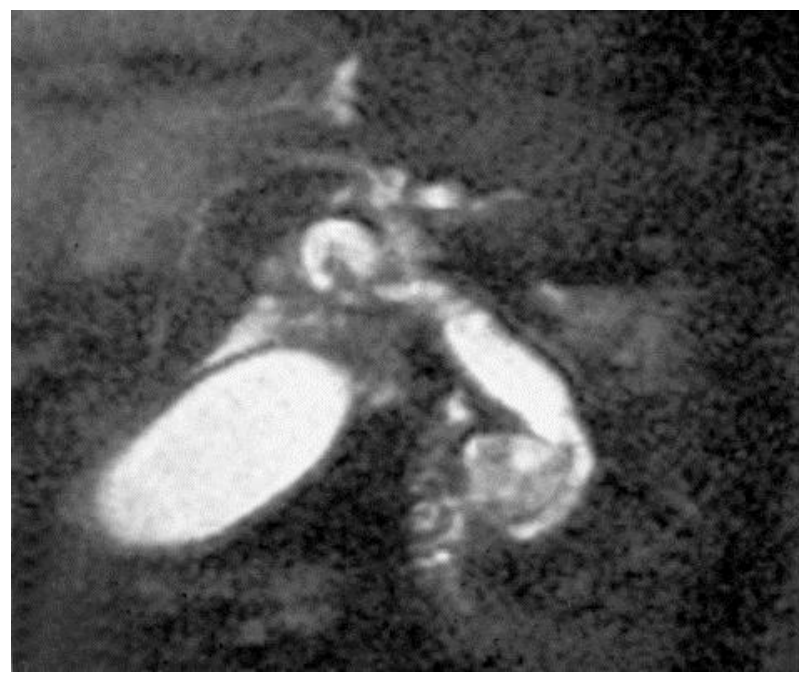

Fig. 1. The diverticulum as seen on MRCP compressing the distal end of the CBD and causing dilatation of its proximal part. 


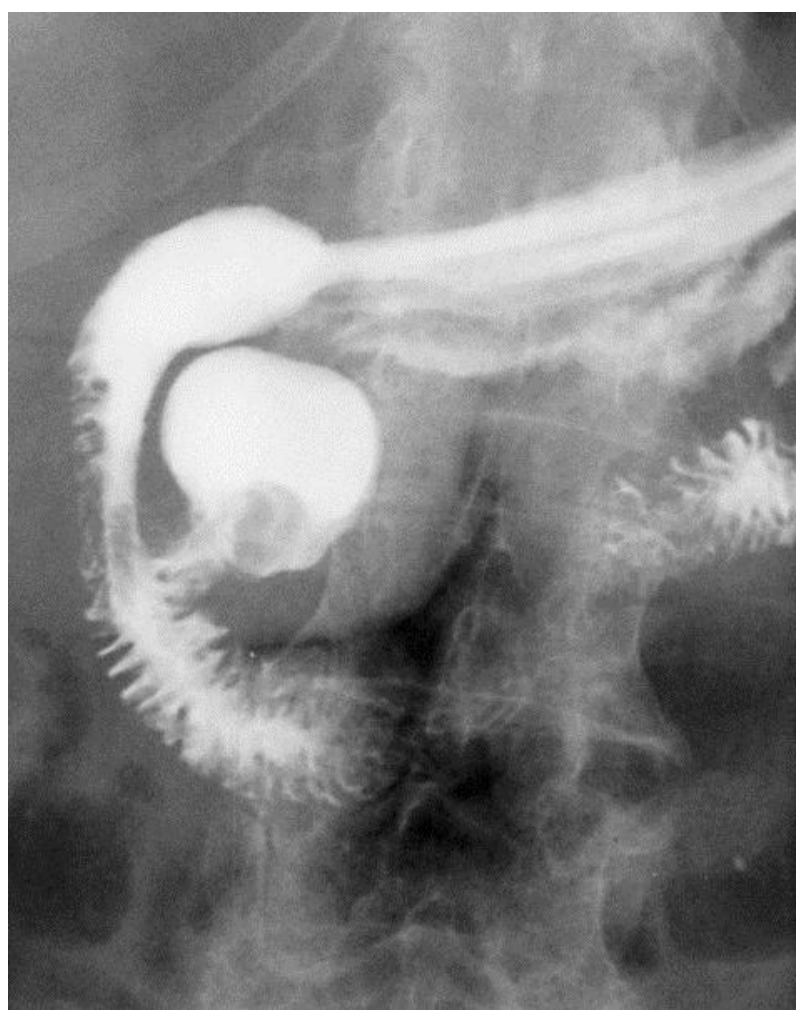

Fig. 2. Hypotonic duodenography disclosed the diverticulum with a filling defect corresponding to the papilla.

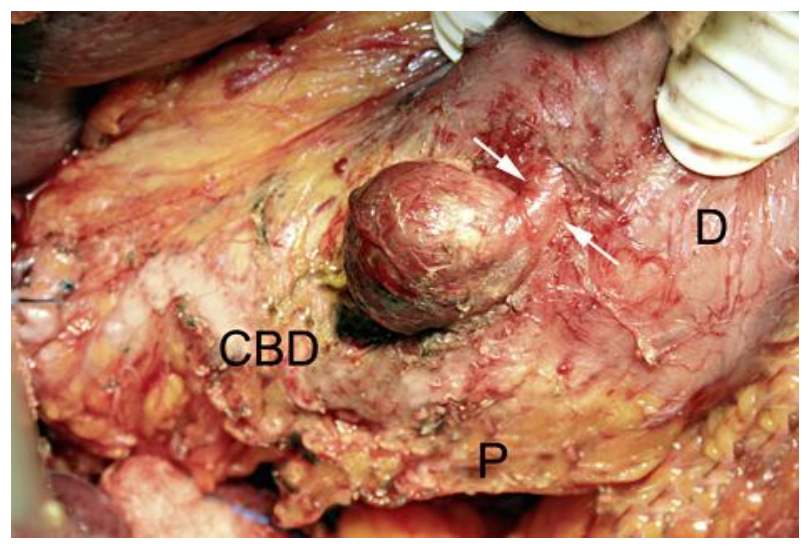

Fig. 3. Intraoperative photograph showing the neck of the diverticulum (arrows) protruding through the duodenal wall, compressing the CBD and distorting its course. $\mathrm{D}=$ Duodenum; $\mathrm{P}=$ pancreatic head. 


\begin{tabular}{r|l|l|l}
$\begin{array}{r}\text { Case Reports in } \\
\text { Gastroenterology }\end{array}$ & $\begin{array}{l}\text { Case Rep Gastroenterol 2012;6:523-529 } \\
\text { DOI: 10.1159/000341955 }\end{array}$ & $\begin{array}{l}\text { Published online: } \\
\text { July 31, } 2012\end{array}$ & $\begin{array}{l}\text { @ 2012 S. Karger AG, Basel } \\
\text { ISSN 1662-0631 } \\
\text { www.karger.com/crg }\end{array}$ \\
\hline
\end{tabular}

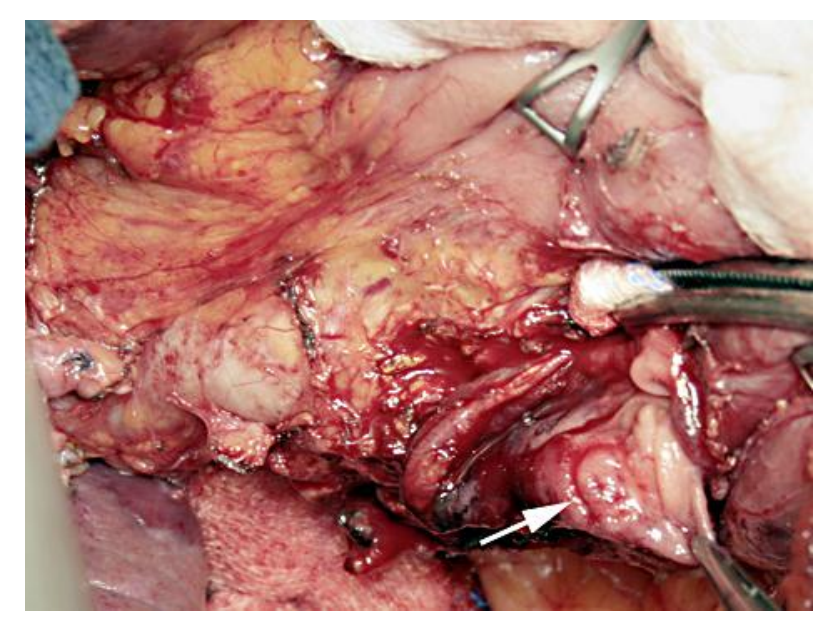

Fig. 4. Intraoperative photograph showing the opened diverticulum with the papilla (arrow) located inside the diverticulum.

\section{References}

1 Lobo DN, Balfour TW, Iftikhar SY, Rowlands BJ: Periampullary diverticula and pancreaticobiliary disease. Br J Surg 1999;86:588-597.

-2 Zoepf T, Zoepf DS, Arnold JC, Benz C, Riemann JF: The relationship between juxtapapillary duodenal diverticula and disorders of the biliopancreatic system: analysis of 350 patients. Gastrointest Endosc 2001;54:56-61.

3 Wu SD, Su Y, Fan Y, Zhang ZH, Wang HL, Kong J, Tian Y: Relationship between intraduodenal peri-ampullary diverticulum and biliary disease in 178 patients undergoing ERCP. Hepatobiliary Pancreat Dis Int 2007;6:299-302.

4 Gudjonsson H, Gamelli RL, Kaye MD: Symptomatic biliary obstruction associated with juxtapapillary duodenal diverticulum. Dig Dis Sci 1988;33:114-121.

-5 Egawa N, Anjiki H, Takuma K, Kamisawa T: Juxtapapillary duodenal diverticula and pancreatobiliary disease. Dig Surg 2010;27:105-109.

6 Castilho Netto JM, Speranzini MB: Ampullary duodenal diverticulum and cholangitis. Sao Paulo Med J 2003;121:173-175.

7 Tan NC, Ibrahim S, Chen CM, Tay KH: Periampullary diverticulum causing biliary stricture and obstruction. Singapore Med J 2005;46:250-251.

8 Vitturi N, Simoni F, De Stefano F, Orlando R, Lirussi F, Realdi G: Paravaterian diverticula presenting as acute cholangitis in two very elderly patients. J Gastrointest Liver Dis 2010;19:220-221.

-9 san Román AL, Moreira VF, García M, Merono E, Boixeda D: Direct compression by a duodenal diverticulum causing common bile duct obstruction. Endoscopy 1994;26:334.

10 Yoneyama F, Miyata K, Ohta H, Takeuchi E, Yamada T, Kobayashi Y: Excision of a juxtapapillary duodenal diverticulum causing biliary obstruction: report of three cases. J Hepatobiliary Pancreat Surg 2004;11: 69-72.

11 Balci NC, Akinci A, Akün E, Klör HU: Juxtapapillary diverticulum: findings on CT and MRI. Clin Imaging 2003;27:82-88.

12 Critchlow JF, Shapiro ME, Silen W: Duodenojejunostomy for the pancreaticobiliary complications of duodenal diverticulum. Ann Surg 1985;202:56-58. 
13 Thomas E, Reddy KR: Cholangitis and pancreatitis due to juxtapapillary duodenal diverticulum. Endoscopic sphincterotomy is the other alternative in selected cases. Am J Gastroenterol 1982;77: 303-304.

14 Buse PE, Edmundowicz SA: Proximal common bile duct obstruction secondary to a periampullary duodenal diverticulum: successful treatment with endoscopic stenting. Gastrointest Endosc 1991;37: 635-637.

15 Chiang TH, Lee YC, Chiu HM, Huang SP, Lin JT, Wang HP: Endoscopic therapeutics for patients with cholangitis caused by the juxtapapillary duodenal diverticulum. Hepatogastroenterology 2006;53: 501-505.

-16 Tyagi P, Sharma P, Sharma BC, Puri AS: Periampullary diverticula and technical success of endoscopic retrograde cholangiopancreatography. Surg Endosc 2009;23:1342-1345. 